\title{
Mentholated cigarettes and smoking cessation: findings from COMMIT
}

\author{
A Hyland, S Garten, G A Giovino, K M Cummings
}

Tobacco Control 2002;11:135-139

See end of article for authors' affiliations

......................

Correspondence to: Andrew Hyland, PhD, Roswell Park Cancer Institute, Department of Cancer Prevention, Epidemiology, and Biostatistics, Elm and Carlton Streets, Buffalo New York 14263, USA; andrew.hyland@ roswellpark.org

Manuscript received 12 November 2001 and revision requested 1 February 2002

Accepted 13 March 2002

\begin{abstract}
Objective: To examine the association between the use of menthol cigarettes and smoking cessation, amount smoked, and time to first cigarette in the morning.

Background: The majority of African American smokers smoke mentholated cigarettes. Some evidence suggests that African Americans may be more nicotine dependent than whites. One theory is that menthol in cigarettes is responsible for enhancing the dependence producing capacity of cigarettes; however, few studies have prospectively examined the association between menthol use and indicators of nicotine dependence.

Methods: Baseline smokers from the Community Intervention Trial for Smoking Cessation (COMMIT) completed a telephone tobacco use survey in 1988 and were re-interviewed in 1993. Use of mentholated cigarettes was assessed by self report at baseline. Indicators of dependence examined were six month cessation in 1993, amount smoked among continuing smokers in 1993, and time to first cigarette in the morning in 1988. Multivariate regression techniques were used to assess the association of baseline menthol use with these outcomes while controlling for other factors related to dependence.

Results: Overall, $24 \%$ of the sample smoked a mentholated brand in 1988. No consistent associations were observed for menthol use and indicators of dependence in both overall and race specific analyses. Factors significantly associated with increased menthol use were female sex, age 25-34 years, African American and Asian race/ethnicity, greater education, greater than 60 minutes to the first cigarette in the morning, two or more past quit attempts, and use of premium brand cigarettes. Canadian respondents and those who smoked 15-24 cigarettes per day had lower rates of menthol use. Use of mentholated cigarettes was not associated with quitting, amount smoked, or time to first cigarette in the morning.
\end{abstract}

Conclusion: Future work is needed to clarify the physiological and sociocultural mechanisms involved in mentholated cigarette smoking.
A estimated one out of five deaths among adults in the USA is attributable to cigarette smoking. ${ }^{1}$ Smoking cessation greatly reduces the risk of disease and premature death. ${ }^{2}$ Lung cancer rates in long term ex-smokers $(>10$ years) are less than half of those found in current smokers. ${ }^{2-4}$ African Americans have higher rates of tobacco-related cancers. ${ }^{5}$

The prevalence of tobacco use among African Americans has decreased from $37.3 \%$ in $1978-80$ to $24.3 \%$ in $1999 .{ }^{5}$ Little national data are available on the use of mentholated cigarettes in adults. In 1986, $76 \%$ of adult African American smokers smoked a mentholated brand compared to $23 \%$ of whites, and $25 \%$ for other race/ethnicities. ${ }^{7}$ In $2000,15.1 \%$ of smokers age 12 years and older reported smoking one of the three most popular brands (Newport, Salem, and Kool) that are only available in mentholated varieties. ${ }^{8}$

African Americans tend to start smoking later in life ( $^{10}$ and smoke fewer cigarettes per day. ${ }^{5}$ Despite these factors, some studies suggest that African American smokers are generally more nicotine dependent than white smokers. Royce and colleagues found that African Americans were more likely to report smoking within the first 10 minutes of waking compared to whites, after controlling for amount smoked and other factors. ${ }^{10}$ Higher concentrations of cotinine in African American smokers have been reported by several groups. ${ }^{11-14}$ In one study, use of mentholated cigarettes was found to significantly contribute to higher cotinine concentrations, even after controlling for race. ${ }^{12}$

Menthol is the main component of peppermint oil, which is obtained from the peppermint plant. Menthol can be applied to cigarettes by adding it directly to the tobacco, adding it to the cigarette filter, or adding it to the cigarette packaging. Menthol has been used as a decongestant and studies show that subjects exposed to menthol report a cooling sensation and the perception of increased nasal airflow, though objective airflow measurements do not show any changes in airway resistance. ${ }^{15-17}$ Menthol has also been used to treat coughing and as an expectorant to promote mucous clearance from the respiratory tract. ${ }^{17}$ One possible mechanism of action is that menthol selectively stimulates cold receptors to produce these effects. ${ }^{17}$ Mentholated cigarettes have been marketed as being "not harsh" and "smooth", which is consistent with the known pharmacological effects of menthol. ${ }^{18}$

The biologic mechanism by which menthol may cause greater nicotine dependence is unclear. One theory is that the menthol makes the smoke easier to inhale more deeply, which facilitates greater nicotine transfer to the body; however, empirical evidence provides weak support for this mechanism. Some investigators have found that persons smoking mentholated cigarettes puff less intensely, but have higher carbon monoxide levels. ${ }^{19}{ }^{20}$ However, Ahijevych and colleagues found carbon monoxide levels were boosted less among those smoking mentholated cigarettes. ${ }^{21}$ Others have found similar puff volumes between menthol and non-menthol smokers..$^{21}$ Another theory is that menthol stimulates the production of saliva, which raises the $\mathrm{pH}$ in the mouth and facilitates greater nicotine absorption, ${ }^{12}$ though this would result in inefficient nicotine transfer and does not explain the carbon monoxide boost. Shields and colleagues found that African Americans with a longer number of variable tandem repeats in their DRD4 dopamine receptor gene had greater signs of nicotine dependence, while no similar effects were found for whites. ${ }^{23}$ 
Thus, genetic variation in nicotinic or dopaminergic pathways by race may also account for the observation that African Americans have similar or greater indicators of nicotine dependence despite smoking fewer cigarettes per day.

Another theory is that menthol selectively stimulates cold receptors in the pulmonary tract, which causes reflexive apnoea or breath holding. ${ }^{12}{ }^{24}$ Breath holding following a puff on a cigarette would increase the transfer of nicotine and other smoke constituents into the body by both increasing the time cigarette smoke is in the lungs, as well as the pressure in the lungs. The only study we are aware of to examine this proposed mechanism was done by Jarvik and colleagues and failed to find differences in the lung retention time in a sample of 19 menthol and non-menthol smokers. ${ }^{19}$

Given that some, but not all, data suggest that African Americans have greater nicotine dependence and that African Americans are much more likely to smoke mentholated cigarette brands, we believed a large scale study to assess the association between menthol use and indicators of nicotine dependence was needed.

\section{METHODS \\ The COMMIT study}

Details of the COMMIT (Community Intervention Trial for Smoking Cessation) study have been published elsewhere. ${ }^{25}$ Briefly, COMMIT was a randomised community based intervention trial for smoking cessation in 11 matched pairs of communities - 10 pairs in the USA and one pair in Canada. Experimental sites received a multifaceted public health intervention to increase cessation rates among smokers such as working with physicians and worksites to increase cessation programmes and services and using mass media to educate the public about tobacco use, smoking cessation, and available resources for smoking cessation. ${ }^{26}$ Use of mentholated cigarettes was neither encouraged nor discouraged in COMMIT.

The COMMIT cohort was identified by a telephone survey in 1988. Only current smokers aged 25-64 years were eligible. The first stage of the survey identified a representative sample of 5400 households within each community to gather information on the age, sex, and smoking patterns of all adults within selected households (response rate $84 \%$ ). In the second stage, a random sample of current smokers aged 25-64 years was selected for an extended interview that included questions about current and past smoking behaviours, brand and type of cigarette usually smoked, interest in quitting smoking, etc (response rate $92 \%$ ).

Approximately $80 \%$ of the smokers initially identified in 1988 were selected to be re-interviewed in 1993 about their tobacco use behaviours. Over the study period, $34 \%$ of the baseline smokers were lost to follow up (29\% unable to locate, $2 \%$ death, $3 \%$ other reasons).

Subjects included in this analysis were smokers between 25-64 years of age at baseline who reported whether their current cigarette brand was mentholated or not in 1988, and had a known smoking status in 1993. A total of 13268 cohort members met these criteria out of the 20347 subjects who originally participated in the COMMIT cohort in 1988.

The primary analysis was to assess whether those who smoked menthol cigarettes at baseline had different rates of future smoking cessation, time to first cigarette, and cigarettes smoked per day. Use of mentholated cigarettes did not differ between experimental and control communities; therefore, we have aggregated the data across these two groups.

Outcome variables: indicators of nicotine dependence The three self reported indicators of nicotine dependence available in the COMMIT study were:

- successful cessation in 1993, measured by a "No" response to the questions "Do you smoke now?" and "Have you smoked any cigarettes in the last six months?"
- amount smoked among continuing smokers in 1993, measured as the weighted average of the number of cigarettes smoked per weekday and weekend day

- time to first cigarette in the morning in 1988, measured by responses to the question, "How soon after you wake up do you have your first cigarette?"; categories used for this analysis are $<10$ minutes and $10+$ minutes.

\section{Predictor variable: use of mentholated cigarettes}

Use of mentholated cigarettes in 1988 was obtained by self reported responses to the question, "What type of cigarettes are the brand that you smoke? Menthol or Plain".

\section{Control variables}

Additional baseline variables used as control variables included sex (male or female), age (25-34 years, 35-44 years, 45-54 years, 55-64 years), race/ethnicity (white, nonHispanic; black, non-Hispanic; Hispanic; other), education $(<12$ years, 12 years, $13-15$ years, $16+$ years $)$, gross household income $(<\$ 10$ 000/year, \$10 000-\$25 000/year, $\$ 25$ 001-\$40 000/year, $>\$ 40$ 000/year), cigarettes smoked per day $(<5,5-14,15-24,25-34,35+)$, time to first cigarette in the morning $(<10$ minutes, $10-30$ minutes, $30-60$ minutes, $>60$ minutes $)$, history of past serious quit attempts (0 attempts, 1 attempt, $>2+$ attempts), age started smoking ( $<16$ years, 16-19 years, > 19 years), desire to stop smoking (none, a little, somewhat, a lot), frequency of alcohol consumption (daily, 3-4 times/week, 1-2 times/week, 1-3 times/month, < l time/month), use a non-cigarette tobacco product (yes or no), pricing tier of cigarette smoked (premium, discount, generic), and the presence of another smoker in the household ( 0 or $1+$ smokers $)$.

\section{Analyses}

Firstly, the characteristics of menthol users and the bivariate association of menthol use with each outcome measure were assessed using simple percentages. To control for the effect of other factors related to menthol use and measures of cessation, regression models were constructed modelling each outcome as a function of each predictor controlling for the control variables outlined above. Logistic models were created to model cessation and time to first cigarette, and linear regression models were used to estimate cigarettes smoked per day. Two tailed 5\% level of significance was used to assess significance. Two way interactions between each control variable and the primary predictor variable, use of menthol cigarettes, were assessed to examine if quitting behaviour in those who used menthol cigarettes differed for subpopulations of smokers.

\section{RESULTS}

Table 1 presents data on the characteristics of mentholated cigarette smokers. Overall, $24 \%$ of smokers reported they smoked a mentholated brand (23\% for whites and 57\% for African Americans). Three brands accounted for the majority of menthol use in this cohort, with Salem being smoked by $27 \%$ of menthol smokers, followed by Kool (17\%), and Newport (14\%). After controlling for covariates, the following factors were associated with increasing menthol utilisation: female sex compared to males; age 25-34 years compared to those age 35-64; African American and Asian race/ethnicity compared to whites; greater education; smoking $<5$ cigarettes per day; greater than 60 minutes to the first cigarette in the morning compared to $<10$ minutes to the first cigarette; two or more past quit attempts compared with no prior attempts to quit; and use of premium brand cigarettes compared to discount/generic cigarettes. Canadian respondents had lower rates of menthol use compared to white US respondents. 
Table 1 Characteristics of menthol users in $1988(n=13268)$

\begin{tabular}{|c|c|c|c|c|}
\hline Characteristic & $\mathrm{n}$ & $\begin{array}{l}\text { Percentage } \\
\text { smoke menthol }\end{array}$ & $\begin{array}{l}\text { OR for } \\
\text { menthol } \\
\text { use* }\end{array}$ & $95 \% \mathrm{Cl}$ \\
\hline \multicolumn{5}{|l|}{ Sex } \\
\hline Male & 6523 & 19.2 & 1.00 & Reference \\
\hline Female & 6745 & 28.7 & 1.72 & 1.57 to 1.89 \\
\hline \multicolumn{5}{|l|}{ Age } \\
\hline 25-34 years & 4212 & 27.8 & 1.00 & Reference \\
\hline $35-44$ years & 4200 & 23.4 & 0.76 & 0.68 to 0.84 \\
\hline $45-54$ years & 2785 & 21.8 & 0.69 & 0.61 to 0.78 \\
\hline $55-64$ years & 2071 & 20.7 & 0.66 & 0.57 to 0.76 \\
\hline \multicolumn{5}{|l|}{ Race/ethnicity } \\
\hline White, non-Hispanic & 10004 & 22.5 & 1.00 & Reference \\
\hline Black, non-Hispanic & 878 & 56.7 & 4.66 & 4.00 to 5.44 \\
\hline Asian & 137 & 38.7 & 2.08 & 1.44 to 3.00 \\
\hline American Indian & 115 & 18.3 & 0.78 & 0.47 to 1.29 \\
\hline Other & 42 & 23.8 & 1.11 & 0.54 to 2.29 \\
\hline Canadian & 1382 & 13.3 & 0.60 & 0.50 to 0.72 \\
\hline Hispanic & 693 & 24.5 & 1.10 & 0.91 to 1.34 \\
\hline \multicolumn{5}{|l|}{ Education } \\
\hline$<12$ years & 2480 & 19.4 & 1.00 & Reference \\
\hline 12 years & 3206 & 22.5 & 1.16 & 1.00 to 1.33 \\
\hline $13-15$ years & 5317 & 26.0 & 1.34 & 1.18 to 1.53 \\
\hline$\geqslant 16$ years & 2239 & 26.7 & 1.43 & 1.23 to 1.67 \\
\hline \multicolumn{5}{|l|}{ Amount smoked in 1988} \\
\hline$<5$ cigs/day & 682 & 32.7 & 1.00 & Reference \\
\hline 6-14 cigs/day & 2322 & 29.8 & 0.89 & 0.72 to 1.09 \\
\hline 15-24 cigs/day & 4736 & 23.2 & 0.79 & 0.64 to 0.98 \\
\hline $25+$ cigs/day & 5516 & 21.3 & 0.85 & 0.68 to 1.06 \\
\hline \multicolumn{5}{|l|}{ Time until first cigarette } \\
\hline$<10$ minutes & 4285 & 22.1 & 1.00 & Reference \\
\hline 10-30 minutes & 3923 & 23.1 & 1.10 & 0.98 to 1.23 \\
\hline $31-60$ minutes & 2405 & 24.0 & 1.09 & 0.96 to 1.25 \\
\hline$>60$ minutes & 2607 & 28.7 & 1.16 & 1.00 to 1.35 \\
\hline \multicolumn{5}{|l|}{ Past attempts to quit } \\
\hline 0 attempts & 8137 & 23.3 & 1.00 & Reference \\
\hline 1 attempt & 2408 & 23.4 & 1.00 & 0.89 to 1.13 \\
\hline $2+$ attempts & 2688 & 27.0 & 1.16 & 1.03 to 1.30 \\
\hline \multicolumn{5}{|l|}{ Age started smoking } \\
\hline$\leqslant 15$ years & 3177 & 23.2 & 1.00 & Reference \\
\hline $16-19$ years & 6533 & 23.7 & 0.92 & 0.82 to 1.02 \\
\hline$\geqslant 20$ years & 3558 & 25.5 & 0.89 & 0.78 to 1.01 \\
\hline \multicolumn{5}{|l|}{ Desire to quit } \\
\hline Not at all & 2172 & 23.0 & 1.00 & Reference \\
\hline A little & 2086 & 23.4 & 0.97 & 0.83 to 1.13 \\
\hline Somewhat & 4094 & 24.9 & 1.02 & 0.89 to 1.17 \\
\hline A lot & 4827 & 24.2 & 0.92 & 0.80 to 1.06 \\
\hline \multicolumn{5}{|l|}{ Frequency of alcohol use } \\
\hline Daily & 1553 & 20.8 & 1.00 & Reference \\
\hline 3-4 times/week & 1274 & 22.9 & 1.03 & 0.85 to 1.24 \\
\hline 1-2 times/week & 3040 & 24.1 & 1.03 & 0.88 to 1.21 \\
\hline $1-3$ times/month & 2270 & 24.7 & 1.00 & 0.84 to 1.18 \\
\hline$<1 /$ month or never & 5037 & 25.1 & 1.07 & 0.92 to 1.24 \\
\hline \multicolumn{5}{|c|}{ Use non-cig product in 1988} \\
\hline No & 12867 & 24.3 & 1.00 & Reference \\
\hline Yes & 397 & 17.4 & 0.76 & 0.57 to 1.02 \\
\hline \multicolumn{5}{|l|}{ Premium brand in 1988} \\
\hline Premium & 12040 & 25.1 & 1.00 & Reference \\
\hline Discount/generic & 774 & 31.3 & 0.49 & 0.39 to 0.61 \\
\hline \multicolumn{5}{|c|}{ Other smokers in the house } \\
\hline No other smokers & 7124 & 24.4 & 1.00 & Reference \\
\hline $1+$ other smokers & 6144 & 23.6 & 1.00 & 0.91 to 1.09 \\
\hline
\end{tabular}

Between 1988 and 1993, 24\% of the baseline smokers had successfully stopped smoking by 1993. In 1988, 32\% of smokers reported smoking within 10 minutes of waking, and the average number of cigarettes smoked per day was 23.2. Among those who continued to smoke in 1993, the average number of cigarettes smoked per day decreased to 21.1 (data not shown).

Figure 1 presents the relative risks for menthol use in 1988 on quitting in 1993 for the entire sample as well as stratified by selected race/ethnicity categories. For the entire sample, the estimated relative risk was 1.00 (95\% confidence interval (CI)
(0.90 to 1.11$)$, and none of the race/ethnicity specific analyses revealed any significant associations.

The analysis of menthol use in 1988 and time to first cigarette in 1988 is presented in fig 2. Overall, menthol users were slightly less likely to report smoking within 10 minutes after waking (relative risk (RR) $0.90,95 \%$ CI 0.81 to 0.99). Race/ethnicity specific analyses show similar effect sizes, though no estimates achieve significance in these reduced sample size models.

No associations were observed between menthol use in 1988 and amount smoked among continuing smokers in 1993 (fig 3). 


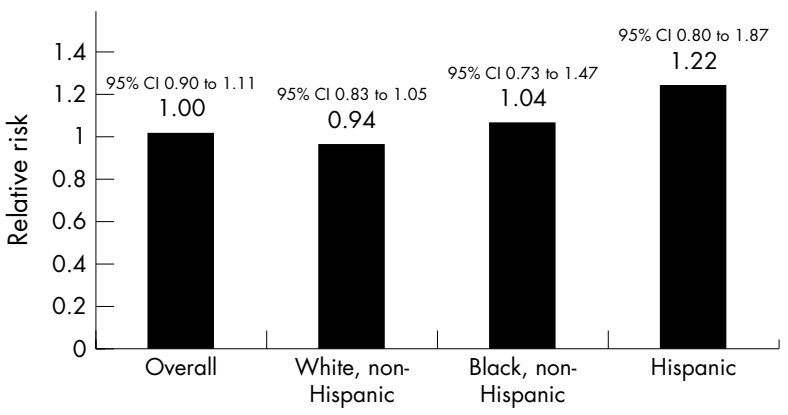

Figure 1 Relative risks for menthol use (1988) on quitting (1993) by race from the COMMIT cohort $(n=13268)$. Analyses control for sex, age, race/ethnicity (in Overall model only), education, cigarettes smoked per day, time to first cigarette in the morning, history of past serious quit attempts, age started smoking, desire to stop smoking, frequency of alcohol consumption, use a non-cigarette tobacco product, pricing tier of cigarette smoked, and the presence of another smoker in the household.

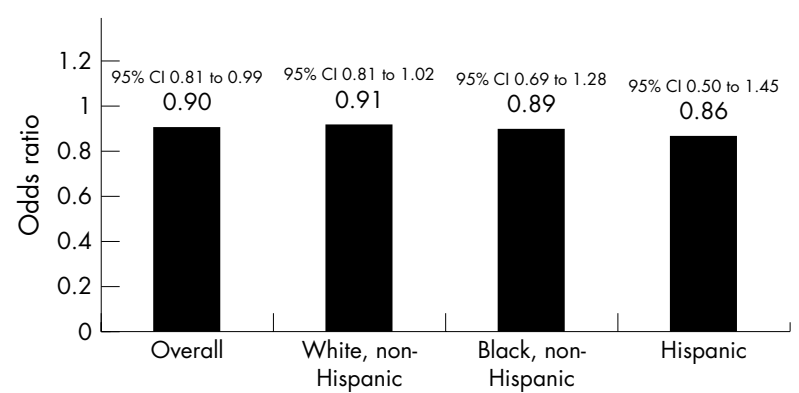

Figure 2 Odds ratios for menthol use (1988) on time to first cigarette in the morning (1988) by race from the COMMIT cohort (n $=13268$ ). Analyses control for sex, age, race/ethnicity (in Overall model only), education, cigarettes smoked per day, history of past serious quit attempts, age started smoking, desire to stop smoking, frequency of alcohol consumption, use a non-cigarette tobacco product, pricing tier of cigarette smoked, and the presence of another smoker in the household.

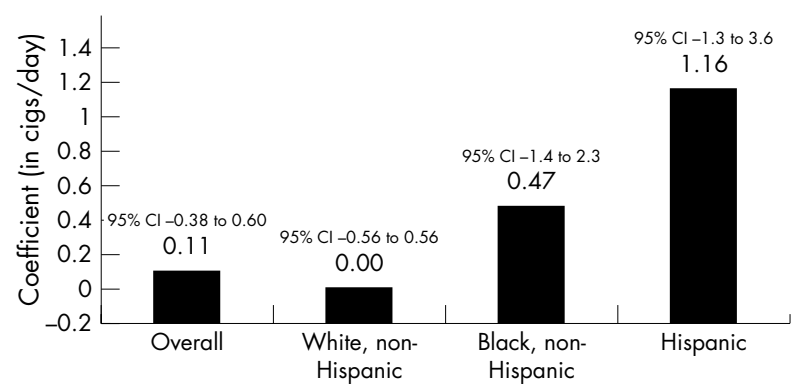

Figure 3 Estimated change in the number of cigarettes smoked per day (1993) associated with menthol use (1988) among continuing smokers by race from the COMMIT cohort $(n=13268)$. Analyses control for sex, age, race/ethnicity (in Overall model only), education, cigarettes smoked per day, time to first cigarette in the morning, history of past serious quit attempts, age started smoking, desire to stop smoking, frequency of alcohol consumption, use a non-cigarette tobacco product, pricing tier of cigarette smoked, and the presence of another smoker in the household.

We also examined any potential interactive effects between menthol use and other variables on each outcome (data not shown). When cessation was the outcome, we found significant interactions between menthol use and indicators of dependence (amount smoked, time to first cigarette, and age started smoking). In each instance, menthol users who had greater levels of dependence had lower quit rates than menthol users who had lower levels of dependence. No significant interactions were observed when the other two outcomes were considered (time to first cigarette and amount smoked).

\section{DISCUSSION}

Despite the biologic mechanism that suggests that menthol may facilitate greater nicotine transfer to the smoker, these data indicate that mentholated cigarette smokers do not exhibit greater signs of nicotine dependence as measured by the likelihood of future cessation, time to first cigarette in the morning, or number of cigarettes smoked per day.

Multiple past quit attempts is significantly associated with menthol use, even after controlling for other factors. It is possible that some smokers who have tried to quit but failed subsequently switch to mentholated cigarettes as a perceived harm reduction technique. Future work should prospectively examine change in smoker behaviour and biologic measures following switching from plain to mentholated cigarettes.

Smoker compensation is a possible explanation that could reconcile the seemingly contradictory findings between the biologic mechanism and the data presented in this paper. Smokers of low yield products tend to compensate their smoking behaviour by inhaling more deeply or covering filter vent holes so that the total body burden of the chemicals in tobacco smoke remain unchanged. ${ }^{27-30}$ Mentholated cigarette smokers may similarly compensate to achieve a desired concentration of nicotine in the body. If this compensation does occur, then it is not surprising that indicators of nicotine dependence are similar between menthol and non-menthol cigarette smokers since nicotine concentrations would be similar in both groups. This may also partially explain the finding that African Americans smoke fewer cigarettes, but have higher cotinine concentrations and comparable or lower cessation rates compared to whites. ${ }^{10}$

Another possible explanation is that the effect of menthol on measures of dependence is relatively weak. Menthol is just one of hundreds of additives to cigarettes, and the measures of dependence used in this study are not as precise as possible. It is reasonable to speculate that an examination of just one additive in isolation of other additives will be unlikely to result in large effects.

Effects of menthol could also possibly exist only in subgroups of smokers, though our analysis did not reveal any consistent significant evidence to support this claim. Given the lack of a biologic mechanism to suggest interactive effects and the inconsistent findings, the single significant finding we observed may have been an artefact. Further study designed to test this specific hypothesis is needed to address this issue.

The major limitation of this study is that more data are needed to test specifically the hypothesis that menthol enhances the transfer of nicotine to the body. The COMMIT study, which was not designed to test this hypothesis, has several limitations relevant to our study. Smoking status was self reported and not biochemically verified, and the measures we used to ascertain nicotine dependence (cigarettes smoked per day and time to first cigarette) are only two components of common indices used to assess nicotine dependence. Studies need to be done that include biologic measurements as well as better measures of nicotine dependence.

Another potential limitation is that menthol use is self reported. Smokers also provided Universal Product Codes that were linked with Federal Trade Commission (FTC) product characteristics, including whether products are mentholated. Agreement between self report and FTC coding was 98\%. Since product code information was unavailable for many respondents, we used the self reported measure. Given the high agreement between self report and FTC coding, we believe this bias to be limited. We are also limited in that menthol status is only assessed at baseline and no information is available on the duration of menthol use. A previous study 


\section{What this paper adds}

Biologic evidence suggests that menthol may enhance the transfer of nicotine and other smoke constituents into the pulmonary system, thereby potentially increasing the dependence producing liability of mentholated cigarettes. A large, prospective study examining the association of mentholated cigarettes and indicators of nicotine dependence does not exist.

This study examined data from 13268 North American smokers followed for five years. No clear associations were observed between menthol cigarette use and indicators of nicotine dependence, even after controlling for race/ethnicity and other demographics. Future research in this area needs to be conducted to reconcile differences between the proposed biologic mechanism and these empirical findings.

using COMMIT data revealed that overall brand switching is relatively low $(\sim 10 \% \text { per year })^{31}$ and only $17 \%$ of baseline menthol smokers had switched to a non-mentholated brand by 1993. These data suggest that baseline menthol smokers in this study may have many years of mentholated cigarette exposure.

In summary, some biologic evidence suggests that menthol may facilitate greater nicotine transfer to the pulmonary system. Despite this mechanism, no clear associations were found between menthol use and three self reported indicators of nicotine dependence in this large, prospective study with data on a variety of measures associated with cessation. Smoker compensation may reconcile the biologic mechanism and the lack of empirical findings, or the failure to find an association may be caused by insensitive exposure and dependence measures or other genetic or biologic factors. Future biologic studies with more sensitive measures of nicotine dependence should be performed to test this hypothesis.

\section{ACKNOWLEDGEMENTS}

The original COMMIT study was funded by the National Cancer Institute. The Roswell Park Cancer Institute Cancer Center Core Grant (CA 16056-26) funded by the National Cancer Institute supported this research. The Core Grant supports the Biostatistics/Biomathematics Core Resource, which contributed to the work presented in this paper.

\section{Authors' affiliations}

A Hyland, S Garten, G A Giovino, K M Cummings, Roswell Park Cancer Institute, Department of Cancer Prevention, Epidemiology, and Biostatistics, Buffalo, New York, USA

Editor's note: Michael Cummings serves as deputy editor and Andrew Hyland as a statistical editor of Tobacco Control. They were excluded from reviewer correspondence and excused themselves from participation in editorial meetings where the manuscript was discussed.

\section{REFERENCES}

1 Connolly GN. Worldwide expansion of transnational tobacco companies. J Ntl Cancer Inst 1992;12:24-35.

2 US Department of Health and Human Services. The health benefits of smoking cessation. A report of the Surgeon General, 1990. Rockville, Maryland: Public Health Service, Centers for Disease Control, Office on Smoking and Health, 1990. (DHHS Publication No (CDC) 90-8416.)

3 Doll R, Peto R. Mortality in relation to smoking: 20 years' observations on male British doctors. BM 1976;2:1525-36.

4 Rogot E, Murray JL. Smoking and causes of death among U.S. veterans: 16 years of observation. Public Health Reports 1980;95:213-22.
5 US Department of Health and Human Services. Tobacco use among U.S. racial/ethnic minority groups: African Americans, American Indians and Alaska Natives, Asian Americans and Pacific Islanders, Hispanics. A report of the Surgeon General, 1998. Atlanta, Georgia: Centers for Disease Control and Prevention, Office on Smoking and Health, 1998. (US Government Printing Office Publication No S/N 017-001-00527-4.)

6 Centers for Disease Control and Prevention. Cigarette smoking among adults - United States, 1999. MMWR Morb Mortal Wkly Rep 2001;40:869-73.

7 US Department of Health and Human Services. Tobacco use in 1986: methods and basic tabulations from adult use of tobacco survey Public Health Service, Centers for Disease Control, Center for Chronic Disease Prevention and Health Promotion.

8 Substance Abuse and Mental Health Services Administration Summary of findings from the 2000 national household survey on drug abuse. Office of Applied Statistics. Department of Health and Human Services. Substance Abuse and Mental Health Services Administration. DHHS Publication No. (SMA) 01-3549. 2001.

9 Sterling TD, Weinkam JJ. Comparison of smoking-related risk factors among black and white males. Am J Ind Med 1989;15:319-33.

10 Royce JM, Hymowitz N, Corbett K, et al. Smoking cessation factors among African Americans and whites. COMMIT research group. Am J Public Health 1993:83:220-6.

11 Wagenknecht LE, Cutter GR, Haley NJ, et al. Racial differences in serum cotinine levels among smokers in the coronary artery risk development in (young) adults study. Am J Public Health 1990;80: 1053-6.

12 Clark PI, Gautam S, Gerson LW. Effect of menthol cigarettes on biochemical markers of smoke exposure among black and white smokers. Chest 1996:110:1194-8.

13 Perez-Stable EJ, Herrera B, Jacob P 3rd, et al. Nicotine metabolism and intake in black and white smokers. JAMA 1998;280:152-6.

14 Caraballo RS, Giovino GA, Pechacek TF, et al. Racial and ethnic differences in serum cotinine levels of cigarette smokers: Third National Health and Nutrition Examination Survey, 1988-1991. JAMA 1998:280:135-9

15 Eccles R, Jones AS. The effect of menthol on nasal resistance to air flow. J Laryngol Otol 1983;97:705-9.

16 Eccles R, Jawad MS, Morris S. The effects of oral administration of (-)-menthol on nasal resistance to airflow and nasal sensation of airflow in subjects suffering from nasal congestion associated with the common cold. J Pharm Pharmacol 1990;42:652-4.

17 Eccles R. Menthol and related cooling compounds. J Pharm Pharmacol 1994;46:618-30.

18 Pollay R. 20th century tobacco ad collection. Collected by Richar Pollay, catalogues by Roswell Park Cancer Institute.http:// www.tobaccodocuments.org/pollay/dirdet.cfm

19 Jarvik ME, Tashkin DP, Caskey NH, et al. Mentholated cigarettes decrease puff volume of smoke and increase carbon monoxide absorption. Physiol Behav 1994;56:563-70.

20 McCarthy WJ, Caskey NH, Jarvik ME, et al. Menthol vs nonmenthol cigarettes: effects on smoking behavior. Am J Public Health 1995;85:67-72.

21 Ahijevych K, Gillespie J, Demirci M, et al. Menthol and nonmenthol cigarettes and smoke exposure in black and white women. Pharmacol Biochem Behav 1996:53:355-60.

22 Caskey NH, Jarvik ME, McCarthy WJ, et al. Rapid smoking of menthol and nonmenthol cigarettes by black and white smokers. Pharmacol Biochem Behav 1993;46:259-63.

23 Shields PG, Lerman C, Audrain J, et al. Dopamine D4 receptors and the risk of cigarette smoking in African-Americans and Caucasians. Cancer Epidemiol Biomarkers Prev 1998:7:453-8.

24 Garten S. Menthol and tobacco smoking. URL: http:// goodhealth.freeservers.com/methtobaccolntro.html.

25 COMMIT Research Group. Community intervention trial for smoking cessation (COMMIT): summary of design and intervention. J Ntl Cancer Inst 1991:83:1620-8.

26 US Department of Health and Human Services. Community-based interventions for smokers: the COMMIT field experience. Smoking and Tobacco Control Monograph No 6. Bethesda, Maryland: Public Health Service, National Institutes of Health, National Cancer Institute, 1995. (NIH Publication No 95-4028.)

27 Kozlowski LT, O'Connor RJ. Official cigarette tar tests are misleading: use a two-stage, compensating test. Lancet 2000;355:2159-61

28 Kozlowski LT, Goldberg ME, Yost BA, et al. Smokers are unaware of the filter vents now on most cigarettes: results of a national survey. Tobacco Control 1996:5:265-70.

29 Kozlowski LT, Pope MA, Lux JE. Prevalence of the misuse of ultra-low ta cigarettes by blocking filter vents. Am J Public Health 1988;78:694-5.

30 Diordjevic MV, Hoffmann D, Hoffmann I. Nicotine regulates smoking patterns. Prev Med 1997;26:435-40.

31 Cummings KM, Hyland $A$, Lewit $E$, et al. Discrepancies in cigarette brand sales and adult market share data: are new teen smokers filling the gap? Tobacco Control 1997;6(suppl 2); S38-42. 